\title{
Parental Involvement, Student Active Engagement and the 'Secondary Slump' Phenomenon-Evidence from a Three-Year Study in a Barbadian Secondary School
}

\author{
Ian A. Marshall ${ }^{1} \&$ Grace-Anne Jackman ${ }^{1}$ \\ ${ }^{1}$ School of Education, University of the West Indies, Cave Hill Campus, Barbados \\ Correspondence: Ian A. Marshall, School of Education, University of the West Indies, Cave Hill Campus, \\ Barbados. Tel: 1-246-417-4549. E-mail:ian.marshall@cavehill.uwi.edu
}

Received: January 29, 2015 Accepted: March 16, 2015 Online Published: June 29, 2015

doi:10.5539/ies.v8n7p84

URL: http://dx.doi.org/10.5539/ies.v8n7p84

\begin{abstract}
Abstact
This study examined the relationship between parental involvement and a proximal student academic outcome-active engagement, for a cohort of 160 students on their transition to secondary school and at three subsequent time periods. The student-reported measures were assessed using the Hoover-Dempsey and Sandler (2005) instrument. Results provide clear evidence of the 'secondary slump' phenomenon with a consistent decline in each of the four parental involvement subscales (parent modeling, parent instruction, parent encouragement, parent reinforcement) and with female students reported significantly higher levels of parental involvement than males. A similar pattern of decline emerged for students' level of active engagement across the three years of the study; however, no gender differences were seen. In addition, the findings suggest a significant positive relationship between each of the four parental involvement constructs and active engagement. In discussing ways to address this 'secondary slump', discussions focused on a revision of the parental involvement instrument to include items which are more reflective of today's increased use of the Internet and social media to facilitate interactions between parents and schools.
\end{abstract}

Keywords: active engagement, Barbados, parental encouragement, parental instruction, parental involvement, parental modeling, parental reinforcement, secondary slump

\section{Introduction}

The issue of parental involvement in secondary school has occupied the attention of school administrators and educational planners in Barbados in recent years. This renewed concerned stems, in part, from the pattern of declining levels of parental involvement at the secondary level. This emerging trend is particularly worrisome given the fact that there is research that consistently underscores the positive relationship between parental involvement and student academic outcomes (Adeymo, 2005; Aunola, Stattin, \& Nurmi, 2000; Chen, 2009; Jeynes, 2007; Kim et al., 2012). These findings underscore the importance of parental involvement and support not only in influencing children's academic success but also in the fostering of strong school-parent partnerships. In a previous study the authors of this paper examined the relationship between parental involvement and student proximal academic outcomes using a sample of students in a secondary school in Barbados. This present paper builds on that research and examines how the relationship evolved over a three year period. To this end the study sought to identify the factors influencing parent involvement and examine the nature and strength of the relationship between parental involvement variables and proximal academic outcomes for students during their first three years at a secondary school in Barbados. On transitioning to secondary school at age eleven, the students completed a survey in which they assessed the level of their parents' involvement based on four parental constructs, namely parent modeling, parent instruction, parent encouragement, and parent reinforcement (Hoover-Dempsey \& Sandler, 1995). The proximal academic outcome was assessed using a measure of student-reported active engagement. Subsequent to this baseline point, follow-up surveys were conducted with this cohort of students at three other time points: at the end of their first, second and third years respectively in secondary school. The longitudinal nature of this study also facilitated an investigation of the 'secondary slump' phenomenon, a term coined by Epstein (2005) which refers to a reduction in the level of parental involvement as students became older. 


\subsection{Theoretical Background}

\subsubsection{Social Cognitive Theory}

The research is based on the sociocultural theory of learning and development which was developed by Vygotsky, (1978) which underscores how social and individual processes interact in the co-construction of knowledge. The central thesis of the sociocultural theory is that learning takes place in cultural contexts and therefore to fully understand how learning takes place one must understand that relationship between learning and social behaviour. A central tenant of Vygotsky's work is the genetic law of development which states that every function in the cultural development of the child comes on the stage twice, in two respects; first in the social, later in the psychological, first in relations between people as interpsychological category, afterwards within the child as an intrapsychological category, therefore all higher psychological functions are internalized relationships of the social kind, and constitute the structure of personality (Valsiner, 1987). Put differently, when beginning an activity, learners depend on others with more experience. Over time they take on increasing responsibility for their own leaning and participation in joint activity (Lave \& Wenger, 1991).This theory is particularly applicable for research on parental involvement and academic achievement because there is evidence (Bandura, 1986; Hoover-Dempsey \& Sandler, 1995) which underscores the relationship between parents' perceptions of their roles, and their sense of efficacy for helping children to succeed and how these factors can significantly influence how they interact with both their children and their teachers. In other words, parents who (i) have had positive experiences while they themselves were students, (ii) good working relationships with teachers and school officials, and (iii) supportive relationships with other parents, then they are more inclined to be involved in the school life of their children, modeling behaviours and creating conditions for social learning that communicate positive messages about learning (Chrispeels \& Rivero, 2001). Additionally, if parents believe that they have the capacity to help their children achieve academically then they would be more likely to become actively involved in the home and school lives of their children, even in the face of challenges (Bandura, 1989). Overall, the theory therefore highlights the role of outcome expectations, perceived self-efficacy, goal setting and self-regulated learning, concepts which come into focus when one begins to examine the relationship between parental involvement and academic engagement. Additionally, the fact that the study is longitudinal in nature provides a further opportunity for one to investigate any sociocultural influences that may have impacted on the findings of the study.

\subsubsection{Parental Involvement and Academic Achievement}

A general overview of the research on the relationship between parental involvement and student academic achievement presents a dichotomy in the operationalization of academic achievement. Researchers who have defined academic achievement strictly in terms of academic indicators, such as scholastic achievement test (SAT) or other standardized test results, national examinations or certification performance have consistently found a positive relationship between the two variables. Jeynes (2007) conducted a meta-analysis in which she evaluated 52 empirical studies that involved more than 300000 participants and found a positive association between parental involvement, defined in the study as "parental participation in the educational processes and experiences of children" and academic achievement outcomes. Across these studies, the Hedge's measure indicated that for overall academic achievement, the effect size for parental expectations was the largest among all the other variables (Hedge's $\mathrm{g}=.88$ ). The remaining variables (i.e., parent-child communication, parents checking homework, and parental style) all showed medium effect sizes, Hedges' $\mathrm{g}=.32, .38$, and .40 respectively, reinforcing the importance and positive effects of parent involvement in schools (Shute et al., 2011).

Conversely, other researchers have used both direct and indirect measures (i.e., motivational constructs) of academic achievement. Unlike the studies which used academic measures of academic achievement, these studies have produced mixed results with regard to the nature of the relationship between parental involvement and these surrogate student achievement measures. Chen (2008) conducted a study which examined student perceptions of parental involvement as measured by the academic involvement of their parents and direct and indirect measures of academic achievement, such as self-reported academic engagement for a sample of grade nine to eleven students in Hong Kong. The results of the structural equation modeling established firstly, that for ninth graders, the indirect relationship of the students-perceived academic achievement was mediated by perceived academic engagement. Secondly, perceived parental involvement was directly and negatively related to academic achievement for all grade levels. Thirdly, that perceived parental involvement predicted academic achievement and fourthly, that higher levels of perceived parental involvement were associated with lower levels of achievement, especially among the tenth graders (Shute, Hansen, Underwood, \& Razzouk, 2011). Al-Alwan (2014) extended the parameters of the discourse to include a discussion of the relationship between parental involvement and motivational constructs such as school engagement, as measured by behavioural engagement, 
emotional engagement and cognitive engagement, and academic performance. Using a sample of 671 ninth and tenth graders, the results of the path analysis suggested that parental involvement influenced school engagement directly and academic performance indirectly through its effects on school engagement. Additionally, the findings revealed that when parents showed an interest in their children, contribute to community building within the school or speak frequently with their children about school-related topics, they directly influence students' perceptions of self, nurture students' level of school engagement and contribute to students' sense of identification with the school. As a result, students are motivated to be engaged both academically and behaviorally (Al-Alwan, 2014).

\subsubsection{Parental Involvement and Student Proximal Academic Outcomes}

Research by Grolnick and Slowiaczek (1994), Hoover-Dempsey et al. (2001), Steinberg, Elmen, and Mounts (1989) suggest that parental involvement may have its most direct and critical influence not on summary measures of achievement, but on student attributes or student proximal academic outcomes that lead to academic success. These researchers posit that parental involvement may therefore be a better predictor of students' proximal outcomes that are associated with achievement (e.g., academic and social self-efficacy, intrinsic motivation for learning and use of self-regulatory strategies) than of traditional academic achievement measures such as standardized examination scores. According to Hoover-Dempsey et al. (2001) students' development of these attributes may mediate the relationship between parental involvement and students' school success. Research by Green (2009), which used the Hoover-Dempsey and Sandler (2005) model of parental involvement and explored the theory of student proximal achievement outcomes, found significant relationships between student-reported parental involvement and student proximal achievement outcomes $(\mathrm{r}=.44, \mathrm{p}<.05)$, as well as significant relationships between parent-reported parental involvement and student proximal achievement outcomes. These findings emphasize not only the relevance of proximal or distal academic outcomes but also their suitability as an appropriate substitute for direct academic achievement measures. Fan and Williams (2009) also looked at indirect effects of parental involvement on academic achievement and found that various dimensions of parental involvement differentially linked to students' engagement in academic activities, senses of self-efficacy and intrinsic motivation in Mathematics and English.

\subsubsection{Gender and Parental Involvement}

It has been suggested that the sex of the child could moderate students' perceptions of parental involvement. Previous research conducted by Chen (2005) revealed that the effect of student-reported perceived academic support from parents and teachers on academic behavior and achievement varied by gender, with females reporting significantly stronger effects. Chen (2005) argued that these findings could be interpreted as reflecting differences in gender socialization, expectations, and bias in Chinese culture. It has been observed that males and females in Chinese culture experience different paths of socialization; males tend to be socialized to become independent and self-regulated, whereas females are socialized to become dependent and submissive (Bond, 1991). This societal valuation and the greater dependent tendency of females due to socialization may explain the stronger effect that student-reported academic support from parents and teachers exert on female students' academic achievement over males. Similarly, a more recent study by Chen (2011) which investigated high school students' perceptions of parental involvement, found differences between males and females in student-reported attitudes towards communication and environmental parental involvement. In particular, while female students preferred to discuss with their parents, especially their mothers, about their interpersonal relationships within the classroom to seek for help and suggestions; male students tended to deal with their own interpersonal relationships within the classroom by themselves rather than consulting with parents. Furthermore, female students were more likely to relate their parents' expressions of expectations and aspirations to 'pressure', whereas male students felt motivated and inspired by the goal and anticipation of academic success set by their parents.

\subsubsection{Declining Levels of Parental Involvement and the Secondary Slump}

From as early as the 1990s the phenomenon of declining parental involvement at the post-elementary level has occupied the attention of researchers. Lee (1995), investigating parental involvement among eighth and tenth graders found that as students move from the middle grades to the early years of high school there was an accompanying decline in parental involvement. Comer (1995) examined the nature of parental involvement during the elementary and middle school years and posited that involvement at the elementary level which consisted mainly of visits to the classroom and interaction with children's teachers tended to increase parents' knowledge about the curriculum, enhance their social capital and increase their effectiveness at home. In contrast, at the middle school level, the involvement shifted to attendance at school activities which was less likely to 
provide middle school parents with information about pedagogy and classroom content or the opportunity to create a mutually effective relationship between parents and teachers. A later study by Catsambis and Garland (1997) which investigated changes in family educational involvement between eighth and twelfth grades found changes in the pattern of parental involvement in adolescents' education between these two grades. Zarate (2007) who explored the issue from the perspective of Latino parents also reported a picture of declining parental involvement. The students in this study recalled that their parents assisted with homework assignments and attended Parent Teacher Conferences and Open Houses more frequently in elementary school than in middle school. In addition, students reported declining assistance with their homework tasks as they progressed through school. In a similar vein, O'neil-Kerr (2014) revealed that parents were very involved in the education of their children when they were in primary school with parents frequently paying visits to their children's school to check on their progress. However, there was a downward shift in the level of parental involvement when their children transitioned to secondary school, with reductions in parental visits to activities such as parents' day and PTA meetings. Dr. Joyce Epstein, director of the Centre on School Family and Community Partnerships reported to Education World (September 25, 2014) that while many schools and districts are able to build a solid volunteer network in the elementary schools, parent involvement and recruitment traditionally drops off in middle and high school. While some maintain that children do not favour having educators and parents 'hanging around' school, Epstein (2014) argued, based on the findings of research of middle and high school students, that although students prefer not to have their parents accompany them on field trips, they do not mind parents volunteering for class and school activities. Whereas, researchers such as Dauber and Epstein (1989) and Hill and Chao (2009) attribute this decline to the large, complex nature of middle schools, thus making it more difficult for parents to become involved, others such as Zarate (2007) propose that the decline in parental involvement is as a consequence of parents' reduced capacity to assist their children with the specific subjects taught in middle school.

In an effort to examine the linkages among all these variables, this study sought to investigate the relationship between parental involvement and proximal academic outcomes as measured by active engagement. In addition, the data were examined to determine whether they provide evidence in support of the 'secondary slump' phenomenon. As a result, the following research questions were formulated:

- What is the pattern of students' perceptions of parental involvement across the three years? Is there a decline in students' perceptions of parental involvement, i.e., is there evidence of a 'secondary slump'?

- Are there statistically significant differences between male and female students' perceptions of parental involvement across the three years?

- What is the pattern of the proximal academic outcome, active engagement, reported by students across the three years?

- What is the relationship between parental involvement and active engagement across the three years?

- To what extent do the parental involvement variables predict active engagement of students across the three years?

\section{Methodology}

\subsection{Sample and Procedure}

The study was conducted across four time periods from September 2012 to June 2014 with a sample of students from a secondary school in Barbados. Permission was obtained from both the school and the parents before the conduct of the study. The questionnaire was first administered to students at the start of the school term, as they transitioned to secondary school from primary school. These students were then resurveyed at three additional time points: at the end of their first, second and third years (grades 6 to 8 ) in secondary school. At the start of the study, the first form (grade 6) population consisted of 160 students aged between 11 and 12 years. However, five of these students refused to participate in the study resulting in a sample size of 155 for this first phase. The numbers of students completing the survey during the three subsequent rounds were 131, 130 and 124 respectively. It must be noted that students were assured of both anonymity and confidentiality and no personal details or identifying data that could be used to link students across the four time periods were collected.

\subsection{Instrumentation}

The Hoover-Dempsey Sandler Parental Involvement Project-Student Questionnaire was the main instrument used for data collection in the study. The instrument consists of sixty-seven (67) items which measure two broad constructs: Parental Involvement and Student Proximal Academic Outcomes. All items were measured using a 4-point Likert scale, 1 = not true, $2=$ a little true, $3=$ pretty true and $4=$ very true, with higher scores indicating 
higher student-reported levels of parental involvement or proximal academic outcomes.

\subsubsection{Parental Involvement}

Parental involvement was operationalized using the following four subscales: Parent modeling, parent instruction, Parent encouragement, and Parent reinforcement. Parent modeling was assessed using a ten-item subscale consisting of items such as: "The person in my family who usually helps me with my homework likes to learn new things" and "The person in my family who usually helps me with my homework knows how to solve problems." Parent instruction was assessed using a 15-item subscale consisting of items such as: "The person in my family who usually helps me with my homework teaches me ways to make my homework fun" and "The person in my family who usually helps me with my homework teaches me to ask questions when I don't understand something." Parent encouragement was assessed using a 12-item subscale consisting of items such as: "The person in my family who usually helps me with my homework encourages me when I don't feel like doing my schoolwork" and The person in my family who usually helps me with my homework encourages me to ask the teacher for help when a problem is hard to solve." Parent reinforcement was assessed using a 13-item subscale consisting of items such as: "The person in my family who usually helps me with my homework shows me that he or she likes it when I stick with a problem until it gets solved" and "The person in my family who usually helps me with my homework shows me that he or she likes it when I try to learn as much as possible."

Reliabilities for each of the four parental involvement variables which were measured using Cronbach's alpha and resulted in acceptable values ranging from.694 to .960 (See Table 1).

\subsubsection{Active Engagement}

Active engagement was used as a measure of student proximal academic outcomes. The active engagement 10-item subscale assessed the extent to which a student engages in behavior and endorses beliefs conducive to achievement (Hoover-Dempsey \& Sandler, 2005) and required students to respond to statements such as: "I try to figure out the hard parts on my own" and "I go back over things that I don't understand." This subscale produced acceptable reliabilities ranging from .754 to .829 (See Table 1).

Table 1. Reliabilities (Cronbach's Alpha) for the parental involvement and student proximal academic outcome (active engagement) scales for the four data collection periods

\begin{tabular}{|c|c|c|c|c|}
\hline Scales & $\begin{array}{l}\text { First Form } \\
\text { (Beginning) } \\
n=160\end{array}$ & $\begin{array}{l}\text { First Form } \\
\text { (End) } \\
\mathbf{n}=131\end{array}$ & $\begin{array}{l}\text { Second Form } \\
\mathbf{n}=130\end{array}$ & $\begin{array}{l}\text { Third Form } \\
\text { n=124 }\end{array}$ \\
\hline \multicolumn{5}{|c|}{ Parent Involvement Scale } \\
\hline Parent Modeling & .694 & .827 & .837 & .807 \\
\hline Parent Instruction & .747 & .868 & .835 & .824 \\
\hline Parent Encouragement & .774 & .881 & .821 & .837 \\
\hline Parent Reinforcement & .797 & .960 & .863 & .887 \\
\hline \multicolumn{5}{|c|}{$\underline{\text { Proximal Academic Outcome }}$} \\
\hline Parent Modeling & .828 & .754 & .783 & .829 \\
\hline
\end{tabular}

\section{Results}

\subsection{Sample Demographics}

For the first round of the study, 155 first-year students (48.4\% female) completed the survey instrument. Table 2 provides a breakdown by gender of the frequencies and percentages of male and female students who participated at the four separate survey times. While both groups reported fluctuating levels of participation throughout the course of the study, the rates of participation were higher for female than the male counterparts (see Table 2). 
Table 2. Distribution of gender for sample across the four survey time periods

\begin{tabular}{lcccccccc}
\hline & \multicolumn{1}{c}{ First Form (Beginning) } & \multicolumn{2}{c}{ First Form (End) } & \multicolumn{2}{c}{ Second Form } & \multicolumn{2}{c}{ Third Form } \\
\cline { 2 - 9 } & $\mathbf{N}$ & $\mathbf{\%}$ & $\mathbf{N}$ & $\mathbf{\%}$ & $\mathbf{N}$ & $\mathbf{\%}$ & $\mathbf{N}$ & $\mathbf{\%}$ \\
\hline Males & 75 & 48.4 & 58 & 44.3 & 62 & 47.7 & 52 & 41.9 \\
Females & 80 & 51.6 & 73 & 55.7 & 68 & 52.3 & 72 & 58.1 \\
& 155 & & 131 & & 130 & & 124 & \\
\hline
\end{tabular}

\subsection{Results by Research Question}

Research Question 1: What is the pattern of students' perceptions of parental involvement across the four survey time periods? Is there evidence of a secondary slump?

To answer this first research question, descriptive statistics in the form of means and standard deviations, for each of the four parental involvement subscales were calculated. Overall students reported relatively high levels of parental involvement on each of the four subscales. For example, on the 10-item parental modeling scale, the means across the four time periods ranged from $3.10(\mathrm{SD}=.522)$ to $3.32(\mathrm{SD}=.425)$. The mean rating based on students' reports of their parents' use of instruction ranged from $3.10(\mathrm{SD}=.466)$ to $3.44(\mathrm{SD}=.375)$. Similarly, over the four time periods, students rated their parents' level of encouragement positively as evidenced by the mean scores which ranged from $3.20(\mathrm{SD}=.514)$ to $3.57(\mathrm{SD}=.375)$. On the 13-item subscale which reported on parent's use of reinforcement, students again provided positive ratings with mean scores ranging from 3.24 $(\mathrm{SD}=.567)$ to $3.62(\mathrm{SD}=.368)$. Interestingly, these results showed a consistent decline on all four of the student-reported parental involvement subscales. In other words, as students move from the start of first year to the completion of their third year in secondary school, their perceptions of their parents' involvement wane, a feature which is characteristic of the secondary slump. These results are summarized in Table 3.

Table 3. Children's perceptions of parental involvement across the four survey time periods

\begin{tabular}{lllll}
\hline & First Form (Beginning) & First Form (End) & Second Form & Third Form \\
\cline { 2 - 5 } & Mean (SD) & Mean (SD) & Mean (SD) & Mean (SD) \\
\hline Parent Modeling & $3.32(.425)$ & $3.30(.534)$ & $3.21(.551)$ & $3.10(.522)$ \\
Parent Instruction & $3.44(.375)$ & $3.37(.504)$ & $3.20(.481)$ & $3.10(.466)$ \\
Parent Encouragement & $3.57(.375)$ & $3.47(.519)$ & $3.34(.464)$ & $3.20(.514)$ \\
Parent Reinforcement & $3.62(.368)$ & $3.35(.803)$ & $3.36(.495)$ & $3.24(.567)$ \\
\hline
\end{tabular}

Research Question 2: Are there statistically significant differences between male and female students' perceptions of parental involvement across the three years.

An independent samples t-test was conducted to determine if there was a significant difference in students' perceptions of the four parental involvement constructs. Overall, females tended to rate the levels of perceived parental involvement higher than the males. More specifically, at the start of their first year, the results revealed significant gender differences on parent instruction $(\mathrm{t}=-2.504, \mathrm{p}<.05)$ and parent reinforcement $(\mathrm{t}=-2.525, \mathrm{p}<.05)$ with females reporting higher levels on these constructs than males. At the end of that year, females again reported significantly higher levels on parent encouragement $(\mathrm{t}=-2.218, \mathrm{p}<.05)$ and parent reinforcement $(\mathrm{t}=-2.293, \mathrm{p}<.05)$ (see Table 4). No significant gender differences were found at the end of the students' second year. However, at the end of third year, differences again emerged with females reporting higher levels of parent reinforcement $(\mathrm{t}=-2.280, \mathrm{p}<.05)$ than males (see Table 5). 
Table 4. Perceptions of Parental Involvement by gender in first year

\begin{tabular}{lcccccc}
\hline & \multicolumn{3}{c}{ First Form } & \multicolumn{3}{c}{ First Form } \\
& (Beginning) & \multicolumn{2}{c}{ (End) } \\
\cline { 2 - 7 } & Male & Female & Sig. & Male & Female & Sig. \\
\hline Parent Modeling & 3.26 & 3.38 & .083 & 3.25 & 3.34 & .339 \\
Parent Instruction & 3.37 & 3.51 & $.013^{*}$ & 3.27 & 3.45 & $.045^{*}$ \\
Parent Encouragement & 3.51 & 3.62 & .087 & 3.37 & 3.57 & $.028^{*}$ \\
Parent Reinforcement & 3.55 & 3.70 & $.014^{*}$ & 3.15 & 3.47 & $.024^{*}$ \\
\hline
\end{tabular}

*-Difference significant at the 0.05 level (2-tailed).

Table 5. Perceptions of Parental Involvement by gender in second and third year

\begin{tabular}{llllllll}
\hline & \multicolumn{3}{c}{ Second Form } & \multicolumn{3}{c}{ Third Form } \\
\cline { 2 - 8 } & Male & Female & Sig. & Male & Female & Sig. \\
\hline Parent Modeling & 3.18 & 3.22 & .649 & 3.08 & 3.11 & .709 \\
Parent Instruction & 3.17 & 3.23 & .468 & 3.01 & 3.16 & .074 \\
Parent Encouragement & 3.29 & 3.36 & .428 & 3.15 & 3.24 & .353 \\
Parent Reinforcement & 3.36 & 3.36 & .949 & 3.11 & 3.34 & $.024^{*}$ \\
\hline
\end{tabular}

*-Difference significant at the 0.05 level (2-tailed).

Research Question 3: What is the level of the proximal academic outcome (active engagement) reported by students across the three years?

Descriptive statistics (means and standard deviations) were used to answer this research question. Overall, the pattern of results showed a consistent decline in the student-reported active engagement. More specifically, students tended to rate their level of active engagement highest at the start of their first year of secondary school $(\mathrm{M}=3.37, \mathrm{SD}=.505)$ but as the students progressed from their first through third years, they reported decreasingly lower levels of active engagement practices. No significant gender differences were revealed at any of the year levels (see Table 6).

Table 6. Descriptive statistics for proximal academic outcomes (active engagement) across the four survey time periods

\begin{tabular}{lllll}
\hline & First Form (Beginning) & $\begin{array}{l}\text { First Form } \\
\text { (End) }\end{array}$ & Second Form & Third Form \\
\cline { 2 - 5 } & Mean (SD) & Mean (SD) & Mean (SD) & Mean (SD) \\
\hline $\begin{array}{l}\text { Active Engagement } \\
\text { Overall }\end{array}$ & $3.37(.505)$ & $3.30(.469)$ & $3.14(.519)$ & $3.06(.553)$ \\
& & & & \\
Males & $3.35(.552)$ & $3.25(.491)$ & $3.17(.512)$ & $3.04(.586)$ \\
Females & $3.39(.460)$ & $3.32(.466)$ & $3.11(.528)$ & $3.09(.539)$ \\
\hline
\end{tabular}

Research Question 4: What is the relationship between parental involvement and active engagement across the three years?

Pearson correlations were used to measure the level of associations between the four parental involvement variables and the student proximal academic outcome, active engagement, across the four survey time periods. The results showed that students' perceptions of parental modeling, instruction, encouragement and reinforcement were all positively associated with higher levels of active engagement. The moderate correlations 
between the parental involvement variables and active engagement were all significant and ranged in value from .34 to .69 . With respect to individual parental involvement variables, active engagement had the strongest correlations with students' perceptions of their parents' instruction ( $\mathrm{rs}=.58$ to .67 ) and the weakest correlations with students' perceptions of how their parents model behavior conducive to achievement (rs $=.34$ to .63 (see Table 7).

Table 7. Relationship between perceptions of parental involvement and active engagement across the four survey time periods

\begin{tabular}{lllll}
\hline & $\begin{array}{l}\text { First Form } \\
\text { (Beginning) }\end{array}$ & $\begin{array}{l}\text { First Form } \\
\text { (End) }\end{array}$ & $\begin{array}{l}\text { Second } \\
\text { Form }\end{array}$ & $\begin{array}{l}\text { Third } \\
\text { Form }\end{array}$ \\
\hline Parent Modeling & $.470^{* *}$ & $.631^{* *}$ & $.391^{* *}$ & $.337^{* *}$ \\
Parent Instruction & $.622^{* *}$ & $.668^{* *}$ & $.577^{* *}$ & $.586^{* *}$ \\
Parent Encouragement & $.524^{* *}$ & $.692^{* *}$ & $.568^{* *}$ & $.570^{* *}$ \\
Parent Reinforcement & $.596^{* *}$ & $.581^{* *}$ & $.593^{* *}$ & $.610^{* *}$ \\
\hline
\end{tabular}

**. Correlation is significant at the 0.01 level (2-tailed).

Research Question 5: To what extent do the parental involvement variables predict active engagement of students across the three years?

Multiple regression analysis was conducted to examine the combined and relative effects of each of the four parental involvement variables on students' perceptions of their active engagement practices. Separate multiple regression equations for each of the four survey periods were modeled, with active engagement as the criterion variable and the four parental involvement variables included as predictors. Results indicated that each of the four overall models were statistically significant $\left(\mathrm{p}_{\mathrm{s}}<.001\right)$. Additionally, the adjusted- $\mathrm{R}^{2}$ values for these full regression models ranged from $.372\left(2^{\text {nd }}\right.$ year $)$ to $.574\left(1^{\text {st }}\right.$ year $)$ which suggests that between $37.2 \%$ and $57.4 \%$ of the variance in student-reported active engagement was explained by the inclusion of four predictors measuring students' perceptions of parental involvement. With respect to the individual contributions, parent reinforcement consistently featured as a significant predictor of students' active engagement across all four time periods. More specifically, at the start of first year, parent instruction $(\beta=.446, p=.001)$ and parent reinforcement $(\beta=.405, \mathrm{p}=.004)$ both significantly contributed to students being actively engaged in their learning. On the completion of their first year, the results indicated that students' active engagement was significantly influenced by parent encouragement $(\beta=.291, \mathrm{p}=.009)$ and parent reinforcement $(\beta=.185$, $\mathrm{p}$ $<.001)$. Parent reinforcement $(\beta=.332, \mathrm{p}=.013)$ again emerged as a significant predictor of students' active engagement at the end of the students' second year at secondary school. Additionally at the end of third year, both parent instruction $(\beta=.349, \mathrm{p}=.021)$ and parent reinforcement $(\beta=.365, \mathrm{p}=.003)$ were again significant predictors of students' perceptions of their active engagement. These regression results are summarized in Table 8 below. 
Table 8. Regression of the four parental involvement constructs on active engagement across the four survey time periods

\begin{tabular}{|c|c|c|c|c|c|c|c|c|}
\hline & \multicolumn{2}{|c|}{ First Form (Beginning) } & \multicolumn{2}{|c|}{$\begin{array}{l}\text { First Form } \\
\text { (End) }\end{array}$} & \multicolumn{2}{|c|}{$\begin{array}{l}\text { Second } \\
\text { Form }\end{array}$} & \multicolumn{2}{|c|}{$\begin{array}{l}\text { Third } \\
\text { Form }\end{array}$} \\
\hline & B & $\mathbf{P}$ & $\boldsymbol{\beta}$ & $\mathbf{p}$ & $\mathbf{B}$ & $\mathbf{p}$ & B & $\mathbf{p}$ \\
\hline Constant & -.152 & & .832 & & .781 & & .758 & \\
\hline Parent Modeling & .140 & .133 & .104 & .209 & -.031 & .715 & -.034 & .704 \\
\hline Parent Instruction & .446 & $.001 * *$ & .143 & .187 & .250 & .076 & .349 & $.021 * *$ \\
\hline Parent Encouragement & .016 & .905 & .291 & $.009 * *$ & .162 & .288 & .044 & .775 \\
\hline Parent Reinforcement & .405 & $.004 * *$ & .185 & $.000 * * *$ & .332 & $.013 * *$ & .365 & $.003^{* *}$ \\
\hline $\mathrm{F}$ & \multicolumn{2}{|c|}{$\mathrm{F}(4,150)=.29 .93$} & \multicolumn{2}{|c|}{$\mathrm{F}(4,131)=46.47$} & \multicolumn{2}{|c|}{$\mathrm{F}(4,128)=20.54$} & \multicolumn{2}{|c|}{$\mathrm{F}(4,124)=4.70$} \\
\hline $\mathrm{p}$-value & \multicolumn{2}{|c|}{$\mathrm{p}<.001$} & \multicolumn{2}{|c|}{$\mathrm{p}<.001$} & \multicolumn{2}{|c|}{$\mathrm{p}<.001$} & \multicolumn{2}{|c|}{$\mathrm{p}<.001$} \\
\hline Adj. R2 & \multicolumn{2}{|l|}{.429} & \multicolumn{2}{|l|}{.574} & \multicolumn{2}{|l|}{.372} & \multicolumn{2}{|l|}{.395} \\
\hline
\end{tabular}

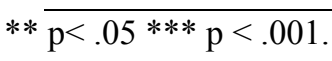

\section{Discussion \& Implications}

Overall, these results provide compelling evidence of the nature of the relationship between parental involvement and proximal academic outcomes as measured by student's active engagement. Firstly, the results revealed a consistent decline in students' perceptions of parental involvement as students' progress from first through third forms. These findings are consistent with those of other researchers (Chen, 2008; Epstein, 2014; O'neil-Kerr, 2014; Zarate, 2007) and reinforce the existence of the secondary slump phenomenon. However, while this atrophy may present some cause for concern, the presence of this phenomenon may also point to the need to revise the traditional models of parental involvement to reflect a more contemporary conceptualisation. In the traditional model, parents' involvement in activities such as field trips, PTA meetings, class visits is emphasised. However, given the increasing role of technology in our lives, it is advised that the Internet and social media be used to involve parents and help keep them abreast of their children's progress and school activities. In follow-up discussions with the principal of the school used in this study as well as with the parents of participating children, the need to make greater use of the Internet and social media as part of the parent-school interaction was repeatedly highlighted. This result is supported by the findings of Zieger and Tan (2012) who asserted that if given access to grades and information through online grade books, most parents would avail themselves of the opportunity to communicate with their children's teachers. Further, school administrators should also be encouraged to use the school's website for the posting of timetables, facilitating parental access to their children's schedules, homework assignments, class tests, and upcoming school activities. Therefore, the argument could be made that if the model used in this study were modified to include this current technological perspective of parental involvement, then the appearance of the 'secondary slump' may not be as pronounced. This suggests the need for a revision of the subscales of traditional PI models to more fully capture the ways in which parents of this millennial generation currently use technology to become involved in the social and academic development of their children. The authors suggest that future research be conducted to examine students' perceptions of parental involvement including both face-to-face and online interactions. Whether parents' use of technology to communicate with school will have a positive impact on proximal academic outcomes such as students' motivation to learn and whether its inclusion will reduce the 'secondary slump' effect are all areas which could be further pursued using a more contemporary technology-focused parental involvement conceptualisation.

Secondly, the finding that female students rated the levels of perceived parental involvement higher than the males is consistent with that of Chen (2005) who attributed this to be reflective of the differences in gender socialization and expectations in Chinese culture, where females are socialized to become dependent and submissive. The early literature on practices in the Caribbean context indicates that gender-based socialization is routine and begins in the early in the children's lives (Cohen, 1956; Moses, 1981; Wilson, 1975). Later research by Bailey (1996) which focused on gender socialisation in the Caribbean concluded that boys are more outwardly directed in their socialization while girls are more inwardly directed. In the context of this research, one would have to conclude that gender stereotypes may have also impacted on the manner in which male and 
female students perceived the involvement of their parents. The fact that there are perceptual differences by gender also highlights the need for gender sensitive parental involvement methodologies with specific reference to instruction and reinforcement.

The pattern of declining levels of student-reported active engagement across the three years mirrored the findings of that with the parental involvement scales and the 'secondary slump' phenomenon discussed earlier. While it is not possible to claim a causal relationship, prior research suggests a positive relationship between parental involvement and student engagement (Christenson \& Sheridan, 2001); therefore the finding that declining levels of parental involvement are accompanied by declining levels of active engagement is in concert with the literature. Confirming these results from previous studies, this study found that students' perceptions of the four parental involvement subconstructs-parental modeling, instruction, encouragement and reinforcement all positively and significantly correlated with higher levels of active engagement. These results are also consistent with that of researchers such as Cotton and Wikelund (2005), Hill and Tyson (2009), Jeynes (2007) and Khajehpoour (2011) who found that when parents are involved intensively in their students' learning, the more beneficial the achievement effects. The challenge, therefore, is for parents to continue to engage in sustainable parental involvement activities and remain relevant to their children as they become older and move through the secondary school years of their education. As a result, it is expected that this parental support will then lead to improved proximal academic outcomes and behaviours that are conducive to achievement (Hong \& Ho, 2005; Hoover-Dempsey \& Sandler, 1997; You \& Sharkey, 2009).

Finally, this study sought to predict the student proximal outcome, active engagement, from the four parental involvement variables across the three years. While parent instruction and parent encouragement were on occasion significant predictors, the construct parent reinforcement was consistently a significant predictor of student-reported active engagement. This finding suggests that students seem to be placing greater emphasis on parental involvement as it relates to reinforcement behaviours that significantly influence student achievement. This is not surprising, as the items in this scale measure the extent to which students perceive that parents reinforce practices and behaviours conducive to achievement during homework involvement. In a sense, the finding is actually highlighting what students value most from their parents, that is, specific help with homework. In the context of Barbadian schools, considerable emphasis is placed on daily homework assignments and its contribution to independent learning. In fact at the secondary level, students are provided with or expected to create their own homework timetables which they are expected to be follow. This may also be the reason why as the students move through the first three form levels, there appears to be a reduction in students' perceptions of parental involvement in their homework activities. However, one cannot ignore the strong influence of the after-school lessons culture in Barbados, which gets stronger as students progress through secondary school and begin preparations for the regional Caribbean Secondary Education Certificate (CSEC) examinations. What may therefore be needed is a revision to the Hoover-Dempsey and Sandler's model to also include items which measure parental involvement with respect to the provision of extra lessons/tutoring for their children. It is quite possible that one may find that this aspect of parental involvement may intensify rather than wane, when one measures the impact of supplementary lessons.

In closing, it must be noted, that while these findings do underscore a positive relationship between parental involvement and proximal academic outcomes, there are several variables such as socio-economic status which were not included in the study but could have a moderating effect on the nature and strength of the relationship between parental involvement and proximal academic outcomes. For example, research by Constantino (2003) pointed to the fact that working parents found it harder to be involved in the academic life of their children. It is anticipated that future studies will endeavor to delve further into parental involvement to discover the nuanced nature of the phenomenon among parents and students from contrasting socio-economic backgrounds, occupational backgrounds and other such biographical variables, which could moderate the relationship between parental involvement and student academic achievement.

\section{Acknowledgments}

The authors wish to express their sincere gratitude to Dr. David Browne, Principal of Queen's College in Barbados for his role in facilitating the data collection over the duration of the study.

\section{References}

Al-Alwan, A. (2014). Modeling the relations among parental involvement, school engagement and academic performance of high school students. International Education Studies, 7(4), 47-56. http://dx.doi.org/10.5539/ies.v7n4p47

Altschul, I. (2012). Linking socioeconomic status to the academic achievement of Mexican American youth 
through parent involvement in education. Journal of the Society for Social Work and Research, 3(1), 13-20. http://dx.doi.org/10.5243/jsswr.2012.2

Bailey, W., Branche, C., McGarrity, G., \& Stewart, S. (1996). Family and gender relationships in the Caribbean. Kingston. Institute of Social and Economic Research, University of the West Indies, Mona.

Bandura, A. (1986). Social foundations of thought and action. Englewood Cliffs, N.J.: Prentice Hall.

Bandura, A. (1997). Self-efficacy: The exercise of control. New York: Freeman.

Blau, I., \& Hameiri, M. (2012). Teacher-families online interaction and gender differences in parental involvement through school data system: Do mothers want to know more about than fathers about their children? Computers \& Education, 59, 701-709. http://dx.doi.org/10.1016/j.compedu.2012.03.012

Chistenson, S., \& Sheridan, S. (2001). School and families: Creating essential connections for learning. New York: Guilford Press.

Chrispeels, J., \& Rivero, E. (2001). Engaging Latino families for student success: How parent education can reshape parents' sense of place in the education of their children. Peabody Journal of Education, 76(2), 119-169. http://dx.doi.org/10.1207/S15327930pje7602_7

Cohen, Y. (1956). Structure and function: Family organization and socialization in a Jamaican community. American Anthropologist, 58, 664-686. http://dx.doi.org/10.1525/aa.1956.58.4.02a00070

Comer, J. (1995). School power: Implications of an intervention project. New York: Free Press.

Constantino, S. (2003). Engaging all families: Creating a positive school culture by putting research into practice. Lanham, MA: Scarecrow Education.

Cotton, K., \& Wikelund, K. (2005). Parental involvement in education. Retrieved from http://www.nwrel.org

Dauber, S., \& Epstein, J. (1989). Parents attitudes and practices of involvement in inner-city elementary and middle schools (Report No. 33). Baltimore, MD: John Hopkins University, Centre for Research on Elementary and Middle Schools.

Desforges, C., \& Abouchaar, A. (2003). The impact of parental involvement, parental support and family education on pupil achievement and adjustment: A literature review. Department for Education and Skills. $\begin{array}{lllll}\text { Research } & \text { Report } & \text { No. } & \text { RR } & \text { Retrieved }\end{array}$ http://www.bgfl.org/bgfl/custom/files_uploaded/uploaded_resources/18617/Desforges.pdf

Desimone, L. (1999). Linking parent involvement with student achievement: Do race and income matter? Journal of Educational Research, 93(1), 11-30. http://dx.doi.org/10.1080/00220679909597625

Deslandes, R., \& Bertrand, R. (2005). Motivation of parent involvement in secondary-level schooling. Journal of Educational Research, 98(3), 164-175. http://dx.doi.org/10.3200/JOER.98.3.164-175

Epstein, J. (2001). School, family, community partnerships: Preparing educators and improving schools. Boulder, CO: Westview.

Epstein, J. (2009). School, family, and community partnerships: Your handbook for action. California, USA: Corwin Press.

Fan, W., \& Williams, C. (2010). The effects of parental involvement on students' academic self-efficacy, engagement and intrinsic motivation. Educational Psychology, 30(1), 53-74. http://dx.doi.org/10.1080/01443410903353302

Fan, X., \& Chen, M. (2001). Parental involvement and students' academic achievement: A meta-analysis. Educational Psychology Review, 13(1), 1-22. http://dx.doi.org/10.1023/A:1009048817385

Ferrara, M. (2009). Broadening the myopic vision of parental involvement. School Community Journal, 19(2), 123-142.

Goldman, R. (2005). Fathers' involvement in their children's education. London: National Family and Parenting Institute.

Gonzalez-Pienda, J. A., Nunez, J. C., Gonzalez-Pumariega, S., Alvarez, L., Roces, C., \& Garcia, M. (2002). A structural equation model of parental involvement, motivational and aptitudinal characteristics, and academic achievement. The Journal of Experimental Education, 70(3), 257-287. http://dx.doi.org/10.1080/00220970209599509

Green, C. L. (2008). Linking parental motivations for involvement and student proximal achievement outcomes 
in home schooling and public schooling settings. Dissertation. Retrieved from etd.library.vanderbilt.edu/03172008/greenclidissertation.pdf

Grolnick, W., Ryan, R. M., \& Deci, E. L. (1991). Inner resources for school achievement: Motivational mediators of children's perceptions of their parents. Journal of Educational Psychology, 83(4), 508-517. http://dx.doi.org/10.1037/0022-0663.83.4.508

Grolnick, W. S., \& Slowiaczek, M. L. (1994). Parent's involvement in children's schooling: A multidimensional conceptionalisation and motivational model. Child Development, 65, $237-252$. http://dx.doi.org/10.2307/1131378

Henderson, A. T., \& Berla, N. (1994). A new generation of evidence: The family is critical to student achievement. Washington, DC: Centre for Law and Education.

Henry, F., \& Wilson, P. (1974). The status of women in Caribbean studies: An overview of their social, economic and sexual roles. Social and Economic Studies, 24, 165-195.

Hill, N. E., \& Chao, R. K. (2009). Families, schools and the adolescent: Connecting research, policy and practice. New York: Teachers College Press.

Hill, N. E., \& Tyson, F. T. (2009). Parental involvement in middle school: A meta-analytic assessment of the strategies that promote achievement. Developmental Psychology, 45(3), 740-763.

Hong, S., \& Ho, H. (2005). Direct and indirect longitudinal effects of parent involvement on student achievement: Second order latent growth modeling across ethnic groups. Journal of Educational Psychology, 97(1), 32-42. http://dx.doi.org/10.1037/0022-0663.97.1.32

Hoover-Dempsey, K. V., \& Sandler, H. M. (1995). Parental involvement in children's education: Why does it make a difference? Teachers College Record, 97, 310-331.

Hoover-Dempsey, K. V., \& Sandler, H. M. (1997). Why do parents become involved in their children's education? Review of Educational Research, 67, 3-42. http://dx.doi.org/10.3102/00346543067001003

Hoover-Dempsey, K. V., \& Sandler, H. M. (2005). Final performance report for OERI Grant \# R305T010673. The social context of parental involvement. A path to enhanced achievement. Presented to Project Monitor Institute of Educational Sciences, U.S. Department of Education, Washington DC.

Hoover-Dempsey, K. V., Battiato, A. C., Walker, J. M. T., Reed, R. P., DeJong, J. M., \& Jones, K. P. (2001). Parental involvement in homework. Educational Psychologist, 36(3), $195-209$. http://dx.doi.org/10.1207/S15326985EP3603_5

Jeynes, W. (2005). A meta-analysis of the relation of parental involvement to urban elementary school student academic achievement. Urban Education, 40(3), 237-269. http://dx.doi.org/10.1177/0042085905274540

Jeynes, W. (2007). The relationship between parental involvement and urban secondary school student academic $\begin{array}{lllll}\text { achievement: A } & \text { meta-analysis. }\end{array}$ http://dx.doi.org/10.1177/0042085906293818

Khajehpour, M. (2011). Relation between emotional intelligence, parental involvement and academic performance of high school students. Procedia Social and Behavioural Sciences, 15, 1081-1086. http://dx.doi.org/10.1016/j.sbspro.2011.03.242

Lave, J., \& Wenger, E. (1991). Situated Learning: Legitimate peripheral participation. NY, Cambridge University Press. http://dx.doi.org/10.1017/cbo9780511815355

Lavenda, O. (2011). Parental involvement in school: A test of Hoover-Dempsey and Sandler's model among Jewish and Arab parents in Israel. Children and Youth Services Review, 33, 927-935. http://dx.doi.org/10.1016/j.childyouth.2010.12.016

Leontiev, A. (1978). Activity, consciousness, personality. Englewood Cliffs, NJ, Prentice Hall.

Lunts, E. (2003). Parental involvement in children's education: Connecting family and school by using telecommunications technologies. Meridian: A Middle School Computer Technologies Journal, 6(1), 1-8.

Martinez-Pons, M. (1996). Test a model of parental inducement of academic self regulation. Journal of Experimental Education, 64, 213-227. http://dx.doi.org/10.1080/00220973.1996.9943804

Moses, T. (1981). Female status, the family and male dominance in a West Indian community. In F. Steady (Ed.), The Black Woman Cross-Culturally. Cambridge, MA: Schenkman Publishing Company. 
Olmstead, C.(2013). Using technology to increase parental involvement in schools. TechTrends, 57(6), 28-37. $\mathrm{http}: / / \mathrm{dx}$.doi.org/10.1007/s11528-013-0699-0

Pajares, F. (2002). Overview of social cognitive theory and of self efficacy. Retrieved 01/07/2013 from http://www.emory.edu/EDUCATION/mfp/eff.html

Patrick, H., Hicks, L., \& Ryan, A. (1997). Relations of perceived social efficacy and social goal pursuit to self-efficacy for academic work. Journal of Early Adolescence, 17, 109-128. http://dx.doi.org/10.1177/0272431697017002001

Peters, M., Seeds, K., Goldstein, A., \& Coleman, N. (2008). Parental involvement in children's education 2007. DCSF Research Report RR034. London, Department for Children, Schools and Families.

Rogoff, B. (1990). Apprenticeship in thinking: Cognitive development in social context. New York: Oxford University Press.

Sanders, M. G., \& Epstein, J. L. (2000). The National Network of Partnership Schools: How research influences educational practice. Journal of Education for Students Placed At Risk, 5(1\&2), 61-76. http://dx.doi.org/10.1080/10824669.2000.9671380

Seginer, R. (2006). Parents' educational involvement: A developmental ecological perspective. Parenting: Science and Practice, 6, 1-48. http://dx.doi.org/10.1207/s15327922par0601_1

Shumow, L., \& Miller, J. (2001). Parents' at-home and at-school involvement with young adolescents. Journal of Early Adolescence, 21, 68-91. http://dx.doi.org/10.1177/0272431601021001004

Shute, V., Hansen, E., Underwood, J., \& Razzouk, R. (2011). A review of the relationship between parental involvement and secondary school students' academic achievement. Educational Research International. http://dx.doi.org/10.1155/2011/915326

Steinberg, L., Elman, J., \& Mounts, N. (1989). Authoritative parenting, psychological maturity, and academic success among adolescents. Child Development, 60, 1424-1436. http://dx.doi.org/10.2307/1130932

Thompson, B. (2008). Characteristics of parent-teacher email communication. Communication Education, 57(2), 201-223. http://dx.doi.org/10.1080/03634520701852050

Valsiner, J. (1987). Culture and the development of children's action: A cultural-historical theory of development. Chichester, UK: Wiley.

Vygotsky, L. (1978). Mind in society. Cambridge, MA: Harvard University Press.

Wong, M. (2008). Perceptions of parental involvement and autonomy support: Their relationship with self-regulation, academic performance, substance use and resilience among adolescents. North American Journal of Psychology, 10(3), 497-518.

You, S., \& Sharkey, J. (2009). Testing a development-ecological model of student engagement: A multilevel latent growth curve analysis. Educational Psychology, 29, 659-684. http://dx.doi.org/10.1080/01443410903206815

Zieger, L., \& Tan, J. (2012). Improving parent involvement in secondary schools through communication technology. Journal of Literacy and Technology, 13(1), 30-54.

\section{Copyrights}

Copyright for this article is retained by the author(s), with first publication rights granted to the journal.

This is an open-access article distributed under the terms and conditions of the Creative Commons Attribution license (http://creativecommons.org/licenses/by/3.0/). 